\title{
Digestibilidade aparente dos nutrientes e energia de ração suplementada com enzimas digestivas exógenas para juvenis de tambaqui (Colosssoma macropomum Cuvier, 1818)
}

\author{
Jorge Antonio Moreira da SILVA¹, Manoel PEREIRA-FILHO², Bruno Adan Sagratzki CAVERO³, Maria
} Inês de OLIVEIRA-PEREIRA²

\begin{abstract}
RESUMO
O experimento foi conduzido com o objetivo de avaliar o efeito da adição de um compelxo multienzimático exógeno composto de amilase, protease, lipase e celulase, em raçôes de juvenis de tambaqui, sobre os coeficientes de digestibilidade aparente (CDa) da proteína bruta $(\mathrm{PB})$, extrato etéreo $(\mathrm{EE})$, carboidratos $(\mathrm{ENN})$ e energia bruta $(\mathrm{EB})$. O delineamento experimental foi inteiramente casualizado com quatro tratamentos (quatro níveis de inclusão de enzimas, 0,0;0,05;0,10; e 0,15\%), três repetiçōes (no tempo) e 10 peixes por unidade experimental. Foram utilizados 40 juvenis de tambaqui, com peso médio de 155,0 $\pm 0,49 \mathrm{~g}$, distribuídos em quatro tanques de alimentação de $500 \mathrm{l}$, recebendo refeiçôes à vontade das 8 às $12 \mathrm{~h}$, a cada hora. Em seguida os animais foram transferidos para coletores de fezes $(200 \mathrm{l})$, onde permaneceram até às $18 \mathrm{~h}$, sendo a coleta de dejetos realizada a cada hora. A determinação dos CDa foi realizada pelo método indireto, sendo utilizado como indicador externo $0,5 \%$ de óxido de cromo-III $\left(\mathrm{Cr}_{2} \mathrm{O}_{3}\right)$ incorporado à ração. Os resultados demonstraram que a suplementação das dietas com enzimas exógenas para juvenis de tambaqui aumenta a digestibilidade aparente dos nutrientes e energia bruta, no nível de inclusão de 0,05\% (P<0,05\%).
\end{abstract}

PALAVRAS-CHAVE

Tambaqui; Colossoma macropomum; digestibilidade aparente; enzimas exógenas; nutrição.

\section{Apparent digestibility of nutrients and crude energy in diets with addition of exogenous digestive enzymes in tambaqui juveniles (Colosssoma macropomum Cuvier, 1818)}

\begin{abstract}
The experiment evaluated the effect of dietary supplementation a multienzyme complex containing amylase, protease, lipase and cellulase for tambaqui juveniles on the apparent digestibility coefficients ( $A D C$ s) of crude protein (CP), ether extract (EE), carbohydrates (CHO) and crude energy (CE). A completely randomized experimental design was used with four treatments (level of enzymes 0.0; 0.05; 0.10; and 0.15 $\%)$ and three replicates (over time), with ten fish per experimental unity. Forty fish weighting $155.0 \pm 0.49 \mathrm{~g}$ were distributed in four 500 Ifeeding tanks and were fed hourly, from 8 to $12 \mathrm{AM}$. After this period, fish were transferred for fecal collection units until 6 PM, where feces were collected hourly. ADCs were evaluated by an indirect method, with $0.5 \%$ III-chromic oxide $\left(\mathrm{Cr}_{2} \mathrm{O}_{3}\right)$ as innert marker. The results showed that supplementary exogenous enzymes on tambaqui diets increased the apparent digestibility of nutrients and crude energy at inclusion level of $0.05 \%(P<0.05 \%)$.
\end{abstract}

KEY-WORDS

Tambaqui; Colossoma macropomum; apparent digestibility; exogenous enzymes; nutrition.

1 Professor do Departamento de Biologia Geral-UFBA-Salvador-BA. CEP: 40170-290. e-mail:jams@ufba.br

2 Pesquisador do Instituto Nacional de Pesquisas da Amazônia - INPA - Manaus-AM. e-mail: pmanoel@inpa.gov.br

3 Professor da Universidade Federal do Amazonas - UFAM - Manaus-AM. e-mail: basc@edu.ufam.br 


\section{INTRODUÇÃo}

O tambaqui (Colossoma macropomum Cuvier, 1818) é uma das espécies de peixe que possui alto valor comercial e grande importância econômica e social na América Latina. A espécie possui potencial para aqüicultura, pois se adapta ao confinamento e arraçoamento. Entretanto, nos atuais modelos de cultivo adotados, os custos com alimentação são relativamente altos, representando o maior percentual dos custos operacionais. Tentativas têm sido realizadas no sentido de baratear esses custos de produção e tornar a atividade da aqüicultura mais atrativa comercialmente. Tem-se a necessidade de se substituir ingredientes de origem animal, item mais caro nas formulaçōes da ração, pelos de origem vegetal, como alternativa para baratear estes custos. Uma alternativa que se apresenta é a substituição de ingredientes tradicionalmente empregados nas raçôes por produtos regionais.

A rápida expansão da aqüicultura depende fundamentalmente de sistemas que usam raçôes balanceadas e de boa qualidade, por permitir o aumento na produtividade de espécies de valor econômico, com menor impacto ambiental. Pezzato (1999) considerou necessário que as raçōes produzidas no Brasil apresentem-se pelo valor biológico dos ingredientes, e não por sua composição química.

A determinação dos coeficientes de digestibilidade tem sido instrumento de grande importância na área da nutrição na aqüicultura, uma vez que pode avaliar ingredientes ou a qualidade das raçôes (Sadiku \& Juancey, 1995). Segundo Pezzato et al. (2002), a determinação dos coeficientes de digestibilidade de subprodutos da agroindústria tem viabilizado o uso de vários ingredientes em raçōes balanceadas para peixes. Em estudos da nutrição de peixes ainda não bastam esses conhecimentos, são necessários mais estudos para aumentar os coeficientes de digestibilidade por meio do processamento adequado dos alimentos, de modo a minimizar o impacto ambiental que esses ingredientes possam causar.

Atualmente, por meio de técnicas de recombinação genética e mutaçōes, a biotecnologia tem possibilitado a produção industrial de enzimas exógenas específicas, utilizando diversos tipos de fungos, bactérias e plantas e tem trazido benefícios no cultivo animal. $\mathrm{O}$ uso de enzimas digestivas exógenas tem despertado atenção para a sua inclusão em raçōes na aquiicultura.

Dentre estes produtos destacam-se a produção de enzimas digestivas exógenas que auxiliam na digestibilidade, inclusive de alimentos de difícil digestão, como ocorrem com algumas espécies quando alimentadas com dietas ricas em carboidratos e proteínas de origem vegetal. Adicionalmente, raçōes com enzimas digestivas exógenas propiciam alta eficiência de aproveitamento, resultando em menor produção de dejetos e diminuem o potencial poluente da atividade. A importância que as enzimas digestivas assumem na utilização de nutrientes pelos peixes, sejam eles estruturais ou energéticos, tem propiciado muitos dados encontrados na literatura (Tengjaroenkul et al., 2000; Gallangher et al., 2001; Kolkovski, 2001; Bordinhon, 2004; Cavero, 2004; Fonseca, 2004; El-Haraoun et al., 2006; Nunes et al., 2006; Oliveira, 2006).

Estudos com o tambaqui, nesta área, propiciaram informaçōes sobre o perfil de enzimas digestivas endógenas, como a atividade da amilase (Kohla et al., 1992), atividade e purificação de proteases (Bezerra, 2000), padróes de atividade específica envolvendo amilase, maltase, protease ácida, tripsina e quimiotripsina (Toniolo, 2001) e estudo da variação circadeana de atividade da amilase, maltase, protease e lipase (Vásquez, 2001).

No mercado brasileiro enzimas industriais podem ser adquiridas e têm sido introduzidas como suplemento em ração animal. Hoje, o uso de enzimas exógenas está mais difundido na alimentação de suínos (Badford, 2000; Teixeira et al., 2005), aves (Garcia, 2000; Tejedor et al., 2001; Fischer, 2002) e coelhos (Yu \& Tsen, 1993; Dias, 1999; Santiago, 2001). Em estudos com aves, Zanella et al. (1999) concluíram que a dieta à base de milho suplementada com amilase reduziu a síntese desta enzima em 23,4\%. Entretanto, são escassas na literatura as informações sobre a utilização de enzimas exógenas em dietas para peixes.

De acordo com Guenter (2002), dentre as principais metas da suplementação enzimática para aves e suínos destacam-se a remoção ou destruição de fatores antinutricionais de grãos; aumentar a digestibilidade da ração; potencializar a ação das enzimas endógenas e diminuir a poluição ambiental causada por nutrientes excretados nas fezes. Enzimas também têm sido utilizadas com o objetivo de incorporar matérias primas de menor qualidade às raçōes de animais domésticos (Nery et al., 2000) e peixes ( $\mathrm{Ng}$ et al., 2002), propiciando menor impacto causado por dejetos e aproveitamento de ingredientes disponíveis a cada região.

Estudos também foram realizados com a introdução de microrganismos adicionados na ração com a finalidade desses organismos secretarem enzimas digestivas para aumentar a digestibilidade dos ingredientes presentes no alimento ou ainda atuar na degradação de fatores antinutricionais (Gildberg et al., 1997; Vine et al., 2004).

Neste sentido, faz-se necessário que sejam realizados estudos sobre alternativas para a melhoria de aproveitamentos de rações pelo tambaqui, sejam elas com novas fontes de ingredientes regionais com potenciais para utilização em rações comerciais, seja com o uso de produtos da biotecnologia disponível no mercado, que possam maximizar sua produção em cultivos a baixo custo no Brasil. O presente trabalho foi conduzido com o objetivo de avaliar o melhor nível de inclusão e o efeito da incorporação de um complexo multienzimático na digestibilidade aparente dos nutrientes e energia bruta de rações para juvenis do tambaqui. 


\section{MATERIAL E MÉTODOS}

O estudo foi realizado no Instituto Nacional de Pesquisas da Amazônia - INPA, Manaus-AM, na Coordenação de Pesquisas em Aqüicultura-CPAQ.

Foram avaliados quatro níveis de inclusão $(0,0 \% ; 0,05 \%$; $0,10 \%$; e $0,15 \%$ ) de um complexo multienzimático composto por levedura seca, amilase, protease e celulase, acrescido ainda com a lipase, fornecidas pela empresa Alltech do Brasil Agroindustrial Ltda. A enzima lipase + o complexo mutienzimático foram misturados à ração com nível abaixo $(0,05 \%)$ e outro acima $(0,15 \%)$ do nível recomendado pelo fabricante $(0,10 \%)$.

Foram utilizadas quatro dietas com níveis crescentes de incorporação do complexo muiti-enzimático exógeno às raçôes (Tabela 1). Todos os ingredientes foram homogeneizados, hidratados e as raçóes foram peletizadas em prensa elétrica, desidratadas por $24 \mathrm{sob}$ circulador de ar e armazenadas em sacos de polietileno em freezer $\left(-20^{\circ} \mathrm{C}\right)$ até o momento do arraçoamento.

Foram utilizados 40 exemplares de juvenis de tambaqui, com peso médio de 155,0 $\pm 0,49 \mathrm{~g}$. O delineamento experimental foi inteiramente casualizado, com quatro tratamentos e três repetições no tempo. Os peixes foram distribuídos em quatro tanques retangulares de alvenaria recobertos por azulejos de cor branca, capacidade para $500 \mathrm{l}$, constituindo-se em unidades de alimentação. Os peixes foram distribuídos ao acaso, com densidade de dez indivíduos em cada

Tabela 1 - Composição percentual e composição centesimal das rações (R) experimentais.

\begin{tabular}{ccccc}
\hline Ingrediente (\%) & Controle & Rl & RII & RIII \\
\hline Milho triturado & 54,50 & 54,40 & 54,30 & 54,20 \\
\hline Farinha de peixe & 29,00 & 29,00 & 29,00 & 29,00 \\
\hline Farelo de soja & 10,00 & 10,00 & 10,00 & 10,00 \\
\hline Farinha de trigo & 5,00 & 5,00 & 5,00 & 5,00 \\
\hline Complexo Enzimático & 0,00 & 0,05 & 0,10 & 0,15 \\
\hline Lipase & 0,00 & 0,05 & 0,10 & 0,15 \\
\hline Suplemento Vit-Mineral & 1,00 & 1,00 & 1,00 & 1,00 \\
\hline Óxido de Cromo-III & 0,50 & 0,50 & 0,50 & 0,50 \\
\hline & Composição centesimal (\%) & & \\
\hline MS & 88,2 & 83,5 & 86,1 & 86,4 \\
\hline PB & 27,6 & 29,9 & 29,8 & 29,1 \\
\hline EE (\%) & 5,1 & 5,4 & 5,4 & 4,9 \\
\hline ENN (\%) & 47,6 & 40,5 & 42,5 & 43,7 \\
\hline FB (\%) & 1,6 & 1,2 & 1,6 & 1,7 \\
\hline MM (\%) & 6,3 & 6,5 & 6,7 & 7,2 \\
\hline EB (kcal/100g) & 399,4 & 386,1 & 393,7 & 389,9 \\
\hline
\end{tabular}

MS = Matéria Seca; $P B$ = Proteína Bruta; EE = Extrato Etéreo; ENN = Extrativo Não Nitrogenado; $\mathrm{FB}=$ Fibra Bruta; $\mathrm{EB}=$ Energia Bruta; $\mathrm{MM}=$ Material Mineral. tanque, localizados no interior de um galpão fechados e cobertos. Os tanques e os coletores de fezes foram abastecidos com água de poço semi-artesiano, com fluxos de entrada e saída de água controlada, provida de aeração constante. Foram adotados sete dias como o período de adaptação dos peixes às condições experimentais.

Os peixes foram mantidos nas unidades de alimentação, sendo apenas retirados após período de alimentação que ocorreu das 08:00 às 12:00 h, onde receberam cinco refeições, à vontade. Após meia hora de alimentados eram transferidas para as unidades de coleta de fezes, compostas por incubadeiras de ovos de peixes adaptadas para este fim, com capacidade para $200 \mathrm{l}$, com fluxo contínuo de água e aeração.

A adaptação consistiu na instalação de dois registros na parte inferior das incubadeiras. Para a coleta de fezes, o registro localizado na parte mais inferior permanecia fechado, enquanto o registro superior permanecia aberto para que as fezes decantassem em um tubo de PVC com dez centímetros de comprimento. No momento da coleta, fechava-se o registro da parte superior e abria-se o registro da parte inferior, por onde as fezes passavam por gravidade e eram coletadas em frasco de vidro e transferidas para placas de Petri constituindo um pool de coletas. As placas com as fezes eram congeladas em freezer $\left(-20^{\circ} \mathrm{C}\right)$ para posterior liofilização, moagem em liquidificador e análises químicobromatológicas.

A operação de coleta de fezes foi realizada sistematicamente de hora em hora, perfazendo um total de cinco coletas diárias, quando então os peixes voltavam para os tanques de alimentação. O período de coleta teve a duração de 30 dias, sendo dez dias para cada repetição. O monitoramento dos parâmetros físicoquímicos da água (oxigênio dissolvido, temperatura e $\mathrm{pH}$ ) foi acompanhado diariamente, pela manhã.

As análises químico-bromatológicas dos ingredientes e das raçōes foram determinadas segundo metodologia proposta pela AOAC. (1995), realizadas em triplicata. A energia bruta (kcal.100g-1) foi calculada utilizando os índices de 5,64 para a proteína bruta, 9,44 para os lipídios e 4,11 para os carboidratos, segundo NRC (1993). Os carboidratos foram obtidos por diferença. Para a determinação do óxido de cromo nas raçôes e nas fezes seguiu-se a técnica descrita por Furukava e Tsukahara (1966). A determinação da digestibilidade das rações foi realizada pelo método indireto, sendo utilizado como indicador externo $0,5 \%$ de óxido de cromo-III $(\mathrm{Cr} 2 \mathrm{O} 3)$ incorporado à ração.

Os coeficientes de digestibilidade total $(\mathrm{Dt})$ e digestibilidade aparente (CDas) dos nutrientes e energia bruta das dietas experimentais foram calculados conforme fórmulas abaixo apresentadas:

$$
\text { Dt }=100-100 * \text { (\% Id } / \% \text { If })
$$

Onde:

$\mathrm{Id}=$ indicador na dieta; $\mathrm{If}$ = indicador nas fezes. 
$\mathrm{CDa}=100-100 *(\% \mathrm{Cr} 2 \mathrm{O} 3$ na ração $/ \% \mathrm{Cr} 2 \mathrm{O} 3$ na fezes $) *$ (\%Nutriente nas fezes/\%Nutiente na ração)

A homogeneidade dos peixes em termos de peso (g) e os coeficientes de digestibilidade aparente $(\mathrm{CDa})$ foram analisados por meio de análise de variância (ANOVA) (teste "F"), a 5\% de probabilidade.

\section{RESULTADOS E DISCUSSÃO}

Os parâmetros físico-químicos da água nos tanques de alimentação, medidos pela manhã, apresentaram valores dentro dos exigidos para o cultivo do tambaqui e, portanto, possivelmente não influenciaram nos resultados dos coeficientes de digestibilidade aparente das dietas experimentais. Em média, o $\mathrm{pH}$, o oxigênio dissolvido e a temperatura ficaram em torno de 7,0 $\pm 0,5 ; 5,3 \pm 0,9$ (mg.l- -1$)$; e $28,3 \pm 0,9\left({ }^{\circ} \mathrm{C}\right)$, respectivamente.

Os resultados referentes aos coeficientes de digestibilidade aparente, com suas repetições, estão apresentados na Tabela 2.

Pelos resultados obtidos para a digestibilidade total (Dt), considerando os valores das três repetiçōes, pode-se observar que houve aumento nos coeficientes de digestibilidade de até $42,1 \%$ com a suplementação do complexo enzimático $(0,05 \%$ de inclusão) na ração. Para a proteína bruta (PB), lipídios (EE), carboidratos (ENN) e energia bruta (EB), os aumentos foram de $19,6 \% ; 15,7 \% ; 35,1 \%$; e 33,5\%, respectivamente, em relação ao controle. Estes resultados corroboram os estudos realizados por Silva et al. (2003) que determinaram os coeficientes de digestibilidade aparente de idêntica formulação e ingredientes da ração controle deste estudo, quando utilizaram tambaquis com peso médio de $1627 \pm 112 \mathrm{~g}$. Os coeficientes de digestibilidade obtidos por estes autores também foram inferiores aos encontrados neste estudo, indicando que a suplementação enzimática aumenta a digestibilidade aparente das rações experimentais avaliadas.

Assim, verifica-se que a adição do complexo enzimático na ração teve efeito positivo, em nível de $0,05 \%$, uma vez que possibilitou maior aproveitamento dos nutrientes e energia bruta pelos juvenis do tambaqui. Segundo Oliveira (2006), na maioria das pesquisas envolvendo a adição de enzimas exógenas em dietas para peixes, os coeficientes de digestibilidade aparente apresentam respostas positivas até um determinado nível de inclusão, demonstrando uma tendência de estabilização ou declínio, o que foi observado nos resultados obtidos nas três repetições desse estudo.

Dentre as várias razōes relativas à inclusão de enzimas na dieta de animais domésticos, uma delas é aumentar a digestibilidade de alimentos crus. Sua efetividade tem sido demonstrada principalmente para cereais menos digeríveis em relação a alimentos de melhor digestibilidade (Bedford, 2000). Quanto melhor a qualidade nutricional da dieta, menor a carga poluente na água e mais eficiente a produção de peixes (Lovell, 1989).
Tabela 2 - Médias dos coeficientes de digestibilidade total aparente, dos nutrientes (PB, EE, ENN) e energia bruta (EB) das dietas (\% da Matéria Seca) e suas repetições.

\begin{tabular}{ccccc}
\hline Coeficiente de digestibilidade (\%) & Controle & $\mathrm{Rl}$ & $\mathrm{RII}$ & $\mathrm{R}$ III \\
\hline Digestibilidade Total (Dt) & $43,8 \mathrm{c}$ & $81,7 \mathrm{a}$ & $80,3 \mathrm{a}$ & $71,0 \mathrm{~b}$ \\
\hline Proteína Bruta (PB) & $73,5 \mathrm{c}$ & $91,5 \mathrm{a}$ & $91,0 \mathrm{a}$ & $83,4 \mathrm{~b}$ \\
\hline Extrato Etérereo (E) & $90,2 \mathrm{~b}$ & $97,3 \mathrm{a}$ & $94,9 \mathrm{a}$ & $94,1 \mathrm{a}$ \\
\hline Extrativo Não Nitrogenado (ENN) & $55,4 \mathrm{c}$ & $88,6 \mathrm{a}$ & $86,1 \mathrm{a}$ & $77,1 \mathrm{~b}$ \\
\hline Energia Bruta (EB) & $54,3 \mathrm{c}$ & $83,5 \mathrm{a}$ & $83,3 \mathrm{a}$ & $75,5 \mathrm{~b}$ \\
\hline
\end{tabular}

Médias seguidas de letras iguais nas linhas não diferem entre si pelo teste $\mathrm{F}$, a $5 \%$ de probabilidade;

Controle $=0 \%$ do complexo enzimático; $\mathrm{Rl}=0,05 \%$ do complexo enzimático;

$\mathrm{R} I \mathrm{l}=0,10 \%$ do complexo enzimático; Rill $=0,15$ do complexo enzimático

\begin{tabular}{ccccc}
\hline Coeficiente de digestibilidade (\%) & Controle & Rl & Rll & RIII \\
\hline Digestibilidade Total (Dt) & $53,6 \mathrm{c}$ & $85,1 \mathrm{a}$ & $68,6 \mathrm{~b}$ & $65,4 \mathrm{~b}$ \\
\hline Proteína Bruta (PB) & $79,0 \mathrm{c}$ & $92,6 \mathrm{a}$ & $84,3 \mathrm{~b}$ & $83,1 \mathrm{~b}$ \\
Extrato Etérereo (E) & $88,6 \mathrm{~b}$ & $97,1 \mathrm{a}$ & $92,4 \mathrm{a}$ & $95,9 \mathrm{a}$ \\
\hline Extrativo Não Nitrogenado (ENN) & $62,1 \mathrm{c}$ & $89,8 \mathrm{a}$ & $75,7 \mathrm{~b}$ & $75,5 \mathrm{~b}$ \\
Energia Bruta (EB) & $62,1,3 \mathrm{c}$ & $87,3 \mathrm{a}$ & $74,8 \mathrm{~b}$ & $70,2 \mathrm{~b}$ \\
\hline
\end{tabular}

Média seguidas de letras iguais nas linhas não diferem entre si pelo teste $\mathrm{F}, \mathrm{a} 5 \%$ de probabilidade;

Controle $=0 \%$ do complexo enzimático; $\mathrm{RI}=0,05 \%$ do complexo enzimático;

$\mathrm{R} \|=0,10 \%$ do complexo enzimático; $R \| I=0,15$ do complexo enzimático.

\begin{tabular}{ccccc}
\hline Coeficiente de digestibilidade (\%) & Controle & RI & RII & RIII \\
\hline Digestibilidade Total (Dt) & $50,0 \mathrm{c}$ & $85,9 \mathrm{a}$ & $73,3 \mathrm{~b}$ & $75,7 \mathrm{~b}$ \\
\hline Proteína Bruta (PB) & $77,5 \mathrm{~b}$ & $93,1 \mathrm{a}$ & $86,2 \mathrm{~b}$ & $86,9 \mathrm{~b}$ \\
Extrato Etérereo (E) & $81,6 \mathrm{~b}$ & $96,4 \mathrm{a}$ & $94,4 \mathrm{a}$ & $95,9 \mathrm{a}$ \\
Extrativo Não Nitrogenado (ENN) & $61,3 \mathrm{c}$ & $90,5 \mathrm{a}$ & $81,0 \mathrm{~b}$ & $81,5 \mathrm{~b}$ \\
\hline Energia Bruta (EB) & $57,6 \mathrm{c}$ & $87,8 \mathrm{a}$ & $77,1 \mathrm{~b}$ & $79,5 \mathrm{~b}$ \\
\hline
\end{tabular}

Média seguidas de letras iguais nas linhas não diferem entre si pelo teste $F$, a $5 \%$ de probabilidade;

A utilização de enzimas exógenas nas rações de suínos e aves reduziu a síntese de enzimas endógenas, disponibilizando mais aminoácidos para a síntese protéica (Yin et al., 2001). Em situações normais, cerca de $25 \%$ das necessidades diárias de proteína são destinadas para síntese de enzimas endógenas em aves. Estes animais, alimentados com ração à base de milho e suplementada com amilase reduziram a síntese desta enzima em 23,4\% (Zanella et al., 1999).

A digestibilidade dos nutrientes presentes na ração pode ser melhorada com o uso de aditivos enzimáticos, que auxiliam no processo digestório (Cavero, 2004). Entretanto, na piscicultura, a adoção e o uso da tecnologia de enzimas exógenas têm sido relativamente lentos (Officer, 2000). Carter et al. (1994) avaliaram o efeito de dieta à base de farinha de soja, suplementada com complexo multi-enzimático (tripsina, protease alcalina, protease ácida, amiloglucosidase, amilase e celulase) para o salmão do Atlântico (Salmo salar L.), concluindo que houve aumento no crescimento e na eficiência da conversão alimentar. $\mathrm{Ng}$ et al. (2002) avaliaram o miolo de palma (PKM) da Malásia, após prétratamento com complexo enzimático comercial (Allzyme Vegpro) 
em rações para tilápia vermelha (Oreochromis sp.), e concluíram que este alimento pode ser incluído em altos níveis, reduzindo custos com a alimentação além de diminuir o impacto. Cavero (2004), avaliando o efeito da adição de protease e lipase exógenas na ração para juvenis de pirarucu (Arapaima gigas), concluiu-se que essas enzimas influenciaram o desempenho zootécnico dos animais. Enquanto que a adição de amilase não apresentou diferença significativa em relação ao tratamento controle, provavelmente por se tratar de espécie carnívora que aproveita melhor os alimentos ricos em proteínas do que carboidratos. $\mathrm{O}$ mesmo autor concluiu que a lipase exógena nas raçôes potencializou a digestão dos lipídios, disponibilizando energia não-protéica. A adição de protease na ração pode neutralizar os efeitos negativos dos fatores antinutricionais da proteína vegetal e otimiza a quebra de moléculas protéicas existentes (Sheppy, 2001).

Bordinhon (2004), trabalhando com a inclusão da amilase em dietas com amido solubilizado para pirarucu (A. gigas), concluiu que o método utilizado para avaliação da atividade de amilase (endógena e exógena), utilizando coeficientes de digestibilidade aparente, não apresentou dados conclusivos quanto à atividade desta enzima no conteúdo intestinal da espécie, o que está de acordo com Hidaldo et al. (1999) de que espécies carnívoras têm baixa atividade da amilase. Entretanto, estudo conduzido por Stone et al. (2003) que, ao utilizarem a enzima aamilase nas dietas para juvenis de Silver Perch (Bidyanus bidyanus), observaram melhores coeficientes de digestibilidade aparente do amido. Segundo Hidalgo et al. (1999) e Baldisserotto (2002), as espécies omnívoras não apresentam problemas de digerir o amido por secretaram a amilase em todas as regióes do intestino, inclusive nos cecos pilóricos do tambaqui (Toniolo, 2001). Fonseca (2004) avaliou o efeito da adição da enzima protease em dietas para o pirarucu (A. gigas) concluindo que houve aumento nos coeficientes de digestibilidade com a substituição da farinha de peixe por proteína de origem vegetal.

Ogunkoya et al. (2006) avaliaram a adição de farelo de soja e complexo enzimático (Superzime CS - xilanase, amilase, celulase, protease e b-glucanase) na dieta de truta arco-íris (Oncorhynchus mykiss) e concluíram que houve pequeno efeito sobre a digestibilidade e nenhum efeito no crescimento.

Os resultados obtidos foram semelhantes em experimentos conduzidos por Nunes et al. (2006) que, ao avaliaram o efeito da adição das enzimas digestivas exógenas observaram que amilase $(0,05 \%)$ e lipase $(0,20 \%)$ adicionadas na ração influenciaram no desempenho zootécnico de juvenis de tambaqui.

Oliveira (2006) avaliou os efeitos da suplementação de ração com um complexo enzimático contendo celulase, protease e amilase sobre a digestibilidade de nutrientes em juvenis de tilápiado-Nilo (Oreochromis niloticus). O autor concluiu que a adição do complexo enzimático à ração, composta à base de farelo de soja e milho, melhora o coeficiente de digestibilidade aparente da matéria seca, proteína bruta, energia bruta, amido, cálcio e fósforo, no nível de $0,05 \%$, o que corrobora com os resultados apresentados para o tambaqui.

A presença da celulase no complexo enzimático pode ter sido um fator em destaque nos resultados alcançados, uma vez que podem ser explicados levando-se em consideração que essa enzima tem ação na degradação dos constituintes das paredes celulares presentes nos ingredientes da ração à base de produtos vegetais, que em conjunto com as xilanases e glucanases, constituem as principais enzimas de degradação dos PNAs (Polissacarídeos NãoAmiláceos), as quais não são sintetizadas pelos não-ruminantes, tornando biodisponíveis os monômeros de carboidratos, proteínas e lipídios das células vegetais para os peixes.

\section{CONCLUSÃO}

O complexo multi-enzimático constituído de amilase, protease, celulase e lipase, quando adicionado à ração de juvenis de tambaqui $(0,05 \%)$, melhora a digestibilidade aparente das raçōes, aumenta o aproveitamento dos nutrientes e energia bruta, desta forma, diminuindo os teores de nutriente dos dejetos, resultando em menor impacto sobre a qualidade da água dos efluentes do cultivo desta espécie.

\section{AGRADECIMENTOS}

Os autores agradecem à FAPEAM - Fundação de Amparo à Pesquisa do Estado do Amazonas, e ao $\mathrm{CNPq}$ - Conselho Nacional do Desenvolvimento Científico e Tecnológico, pelo apoio financeiro.

\section{BIBLIOGRAFIA CITADA}

AOAC. 1995. Association of Official Analytical Chemists/Official methods of analysis. 17ed., Arlington. 1141pp.

Baldisserotto, B. 2002. Fisiologia de peixes aplicada à piscicultura. Santa Maria, Ed. da UFSM., Santa Maria, Rio Grande do Sul. 92pp.

Bedford, M.R. 2000. Exogenus enzymes in monogastric nutrition their current value and future benefits. Animal Feed Science and Technology, 86: 1-13.

Bezerra, R.S. 2000. Proteases digestivas no tambaqui (Colossoma macropomum, Cuvier, 1818). Tese de Doutorado, Universidade Federal de Pernambuco, Recife, Pernambuco. 136pp.

Bordinhon, A.M. 2004. Suplementação de amilase e solubilidade de amido na digestibilidade da ração para pirarucu Arapaima gigas. Dissertação Mestrado, Instituto Nacional de Pesquisas da Amazônia/Universidade Federal do Amazonas. Manaus, Amazonas. 30pp.

Carter, C.G.; Houlihan, D.F.; Buchanan, B.; Mitchell, A.I. 1994. Growth and feed utilization efficiencies of seawater Atlantic salmon Salmo solar L., fed a diet containing supplementary enzymes. Aquaculture and Fisheries Management, 25: 37-46. 
Cavero, B.A.S. 2004. Uso de enzimas digestivas exógenas na alimentação de juvenis de pirarucu, Arapaima gigas (Cuvier, 1829). Tese de Doutorado, Instituto Nacional de Pesquisas da Amazônia/ Universidade Federal do Amazonas. Manaus, Amazonas. 79pp.

Dias, J.C.C.A. 1999. Niveis decrescentes de proteina em dietas suplementadas com complexo enzimático para coelhos em crescimento. Dissertação de Mestrado, Universidade Federal de Minas Gerais, Belo Horizonte, Minas Gerais. 89pp.

El-Haroun, E.R.; Goda, A.M.A-S.; Kabir Chowdhury, M.A. 2006. Effect of dietary probiotic Biogen supplementattion as a growth promoter on growth performance and feed utilization of Nile tilapia Oreochomis niloticus (L.). Aquaculture Research, 37:14731480.

Fonseca, F.A.L. 2004. Substituição de farinha de peixe por proteina de origem vegetal com adição de protease exógena na digestibilidade de ração para juvenis de pirarucu (Arapaima gigas). Dissertação de Mestrado, Instituto Nacional de Pesquisas da Amazônia/ Universidade Federal do Amazonas, Manaus, Amazonas. 41pp.

Fischer, G.; Maier, J.C.; Rutz, F.; Bermudez, V.L. 2002. Desempenho de frangos de corte alimentados com dietas à base de milho e farelo de soja, com ou sem adição de enzimas. Rev. Bras. Zootec., 31(1):402-410.

Furukava, A.; Tsukahara, H. 1966. On the acid digestion method for the determination of chromic oxide as in index substance in the study of digestibility of fish feed. Bulletin of the Japanese Society of Scientific Fisheries, 32(6): 502-506.

Garcia, E.R.M.; Murakami, A.E.; Branco, A.F.; Furlan, A.C.; Moreira, I. 2000. Efeito da suplementação enzimática em raçōes com farelo de soja e soja integral extrusada sobre a digestibilidade de nutrientes, o fluxo de nutrientes na digesta ileal e o desempenho de frangos. Rev. Bras. Zootec., 29(5): 1414-1426,

Gallangher, M.L.; Luczkover, J.J.; Stellwag, E.J. 2001. Characterization of the ultrastructure of the gastrointestinal tract mucosa, stomach contents and liver enzymes activity of pinfish during development. Journal of fish Biology, 58: 17041713.

Gildberg, A.; Mikkelsen, H. 1997. Probiotic effect of latic acid bacteria in the feed on growth and survival of fry of Atlantic cod (Godus morhua). Hydrobiologia, 352: 279-285.

Guenter, W. 2002. Pratical experience with the use of enzymes. (http//www.idrc.ca/books/focus/821/chp6.html). Acesso: 05/ 09/2004.

Hidalgo, M.C.; Urea, E.; Sanz, A.1999. Comparative study of digestive enzymes in fish with different nutritional habits. Proteolytic and Amylase activities. Aquaculture, 170: 267-283.

Kohla, U.; Saint-Paul, U.; Friebe, J.; Wernicke, D.; Hilge, V.; Braum, E.; Gropp, J. 1992. Growth, digestive enzyme activities and hepatic glycogen levels in juvenile Colossoma macropomum Cuvier from South America during feeding, starvation and refeeding. Aquaculture and Fisheries Management, 23: 189-208.

Kolkovski, S. 2001. Digestive enzymes in fish larvae and juveniles implications and applications to formulated diets. Aquaculture, 200: 181-201.
Lovell, T. 1989. Nutririon and feeding offish. Van Nostrand Reinhold, New York, USA. 260pp.

Nery, V.L.H.; Lima, J.A. F.; Nelo, R.C.A. 2000. Adição de enzimas exógenas para leitões dos 10 aos $30 \mathrm{Kg}$ de peso. Rev. Bras. de Zootec., 29(3):794-802.

Ng, W-K.; Lim, H-A.; Lim, S-L.; Ibrahim, C-O. 2002. Nutritive value of palm kernel meal pretreated with enzyme or fermented with Trichoderma koningii (Oudemans) as a dietary ingredient for red hybrid tilapia (Oreochromis sp.). Aquaculture Research, 33:1199-1207.

NRC (National Research Council). 1993. Nutrient Requirement of fish. Academy Press, Washington DC. 114pp.

Nunes, E.S.S.; Cavero, B.A.S.; Pereira-Filho, M.; Roubach, R. 2006. Enzimas digestivas exógenas na alimentação de juvenis de tambaqui. Pesq. agropec. bras., 41(1):139-143.

Officer, D.I. 2000. Feed enzymes. In: D'Mello, J.P.F. (Ed.). Farm animal metabolism and nutrition. The Scottish Agricultural College, Edinburgh, UK. p. 405-426.

Ogunkoya, A.E.; Page, G.I.; Adewolu, M.A.; Bureau, D.P. 2006 Dietary incorporation of soybean meal and exogenous enzyme cocktail can affect physical characteristics of faecal material egested by rainbow trout (Oncorhynchus mykiss). Aquaculture, 254:466-475.

Oliveira, G.R. 2006. Digestibilidade de nutrientes em ração comk complexo enzimático para tilápia-do-Nilo (Oreochromis niloticus). Dissertação de Mestrado, Universidade Federal de Lavras, Lavras, Minas Gerais. 102pp.

Pezzato, L.E. 1999. Alimentação de peixes - Relação custo e benefício. In: Reunião Anual da Sociedade Brasileira de Zootecnia, 36, Porto Alegre: SBZ, 109-118.

Pezzato, L.E.; Miranda, E.C. de; Barros, M.M.; Pinto, L.G.Q.; Furuya, W.M.; Pezzato, A.C. 2002. Digestibilidade Aparente de Ingredientes pela Tilápia do Nilo (Oreochromis niloticus). $R$. Bras. Zootec., 31(4):1595-1604.

Sadiku, S.O.E.; Juancey, K. 1995. Digestibility, apparent amino acid availability and waste generation potential of soybean flour: poultry meat meal blend based diets for tilapia, Oreochromis niloticus (L.), fingerlings. Aquaculture Research, 26:651-657.

Santiago, G.S. 2001. Suplementação enzimática a dietas com diferentes teores e fontes de proteina para coelhos em crescimento. Tese de doutorado, Universidade Federal de Minas Gerais. Belo Horizonte, Minas Gerais. 98pp.

Sheppy, C. 2001. The current feed enzyme market and likely trends. In: Bedfors, M. Partridge, G. (Rds). Enzymes in farm animal nutrition. Finnfeeds International, Marlborough, Wiltshire, UK. p. $1-10$.

Silva, J.A.M.; Pereira-Filho, M; Oliveira-Pereira, M.I. 2003. Frutos e sementes consumidos pelo tambaqui, Colossoma macropomum (Cuvier, 1818) incorporados em raçôes. I. Digestibilidade e velocidade de trânsito pelo trato gastrointestinal. Rev. Bras. Zootec., 32 (6):1815-1824.

Stone, D.A.J.; Allan, G.L.; Anderson, A.J. Carbohydrate utilization by juvenile silver perch, Bidyanus bidyanus (Mitchell). II. 2003. 
Digestibility and utilization of starch and its breakdown products. Aquaculture Research, 34(2):109-121.

Teixeira, A.O.; Lopes, D. C.; Ferreira, V. P. A.; Pena, S. M.; Nogueira, E. T.; Moreira, J. A.; Bünzen, S.; Nery, L. R. 2005. Utilização de enzimas exógenas em dietas com diferentes fontes e níveis de proteína para leitōes na fase de creche. R. Bras. Zootec, 34(3):900906.

Tejedor, A.A.; Albino, L.F.T., Rostagno, H.S. 2001. Efeito da adição de enzimas em dietas de frangos de corte à base de milho e farelo de soja sobre a digestibilidade ileal de nutrientes. Rev. Bras. Zootec., 30 (3):809-816.

Tengjaroenkul, B.; Smith, B.J.; Caceci, T.; Smith, S.A. 2000. Distribution of intestinal enzymes activities along the intestinal tract of cultured Nile tilapia, Oreochromis niloticus L. Aquaculture, 182:317-327.

Toniolo, C.F.C. 2001. Estudo dos padröes de digestão enzimática e perfil metabólico em tambaqui, Colossoma macropomum (Cuvier, 1818), alimentado com diferentes teores de proteina e carboidrato em regime de confinamento. Tese de Doutorado, Universidade Federal de São Carlos. São Carlos, São Paulo. 116pp.

Vásquez, K.L. 2001. Variação circadiana da atividade das enzimas digestivas amilase, maltase, protease e lipase em juvenis de tambaqui, Colossoma macropomum CUVIER, 1818 (CHARACIFORMES,
SERRASALMIDAE). Dissertação de Mestrado. Universidade do Amazonas/Instituto Nacional de Pesquisas da Amazônia. Manaus, Amazonas. 56pp.

Vine, N.G.; Leukes, W.D.; Kaiser, H. 2004. In vitro growth characteristics of five candidate aquaculture probiotcs and two fish pathigens growt in fish intestinal mucus. FMES Microbiology Letters, 231:145-152.

Yin, Y.-L.; Baidoo, S.K.; Jin, L.Z.; Liu, Y.G.; Schulze, H.; Simmins, P.H. 2001. The effect of different carbohydrase and protease supplementation on apparent (ileal and overall) digestibility of nutrients of five hulless barley varieties in young pigs. Livestock Production Science, (71) 2-3:109-120.

Yu, B.; Tsen, H.Y. 1993. An in vitro assessement of several enzymes for the supplementation of rabbit diets. Animal Feed Science and Technology, 40(4):309-320.

Zanella, I.; Sakomura, N.K.; Silversides, F.G. 1999. Efeito da adição de enzimas exógenas na dieta sobre a atividade enzimática da amilase e tripsina pancreática em frangos de corte. Anais da Conferência APINCO 99 de Ciência e Tecnologia Avícolas, 92: 45-52.

Recebido em 15/04/2007

Aceito em 23/01/2007 
